out twice daily as a routine measure. Had we done this we should no doubt have avoided the convulsions which were at one time so frequent and so severe and were evidently the result of the absorption of toxic material from a dilated stomach. Abdominal massage with cod-liver oil was resorted to in despair but from the progress of the case we cannot help thinking that a certain amount is absorbed through the skin and that a certain proportion of the success of the treatment is due to the oil so absorbed.

\section{SUBDIAPHRAGMATIC TRANSPERITONEAL MASSAGE OF THE HEART AS A MEANS OF RESUSCITATION.}

BY H. M. W. GRAY, M.B. ABerd., F.R.C.S. EDIN., BURGFON TO THE $\triangle$ BERDEEN ROYAL INFIRMARY.

A FEMALE patient, aged 55 years, was admitted to hospital at 11.45 A.M. on Feb. 23rd, 1905, suffering from marked laryngeal obstruction. She had travelled nearly 30 miles by carriage and train, accompanied by her medical attendant. He was surprised that she had borne the journey so well considering that she had been suffering for about three months previously from increasing dyspncea which beoame very urgent at times when the patient was exoited. For the past three or four days this had been severe, compelling her to acquiesce in removal to hospital. On arrival she was deeply cyanosed, inspiration was much obstructed and accompanied by a very harsh "baa-ing" nolse, and expiration was also interfered with. She was quite conscious and able to reply to questions, though with difficulty. No intralaryngeal examination was made. It was thought that the dyspncas would subside with rest in bed and orders were given to prepare for tracheotomy immediately after 1 P.M., at which time I should have finished with a clinical lecture in the neighbouring ward. At $12.53 \mathrm{I}$ was told that the patient was dying. On the way to the women's ward a nurse met me saying that she was dead. On entering the ward I heard her make a feeble choky inspiratory effort. Her face was very deeply cyanosed, the large veins standing out on her face and neck. This, however, disappeared with striking rapidity. High tracheotomy was performed at once with a penknife and the lips of the tracheal wound were retracted with bent hairpins. Very little bleeding occurred from a small vein at the lower end of the wound in the neck. Artificial respiration was immediately proceeded with bat only four or five spontaneous breaths were taken by the patient. There was no pulse at the wrist or cardiac impulse from the first. No cardiac sounds could be heard on auscultation. She was pallid, all reflexes had disappeared, the pupils were widely dilated, the muscles became absolutely flaccid, her lips were pale, and her eyes rapidly assumed a "glassy" look. Various methods of resuscitation, including attempted external massage of the heart, were carried out but all to no purpose.

Four or five minutes after the tracheotomy was done the abdomen was opened in the middle line immediately under the xiphoid cartilage, again with my penknife. There was no bleeding. Inserting two fingers I could easily palpate the outline of the heart between the diaphragm and the ribs in front. It was absolutely flaccid. Massage by intermittent pressure was carried out for about four minutes. The compressions were performed about the rate of 70 to 90 per minute. At the end of every 15 to 30 seconds I abated the movements in order to feel any change in the condition of the heart. At the end of the above period I felt the heart becoming firm gradually. After remaining thus for a few seconds a slight tremor was felt. Then very slowly (from 30 to 40 to the minute) the heart began to beat. The pulsations were at first very feeble. I massaged the heart for a few seconds more and then it beat gradually more strongly and quickly until at seven minutes past one it was beating at the rate of about 90 , and more vigorously than since admission. The gradual return of the heart's action was indicated to those around by keeping time with my left hand, the other being used for massage. The colour was observed to return to the face and lips, the eyes lost their "glassy" stare, the pupils contracted, and pulsation of the carotids became very visible.
During all this time artificial respiration had been kept up by compressing the chest. Very soon after the heart began to beat the patient took a rather deep spontaneous breath and from ten to 15 seconds later another, till by degrees respiration became normal though somewhat frequent. Slight hæmorrhage occurred from the abdominal wound which was then partially sutured and a gauze drain was inserted under the diaphragm. When I left the hospital an hour later the pulse was rather weaker and quicker but still wonderfully good, so that I was rather surprised to hear from the house surgeon that the patient died at 3 P.M., having never regained consciousness. The cause of the laryngeal obstruction was found to be a fairly large cancerous growth. Probably at least ten minutes elapsed between the times when the heart stopped beating and when it began again. Crile records the case of a man whose heart stopped for nine minutes and by the combined effect of artificial respiration, infusion of adrenalin, and manual compression of the heart the cardiac action was restored for 31 minutes.

In December, 1902, I had a similar, though not so striking, experience. I was then removing an ovarian cystoma from a woman, aged 60 years. The pedicle of the growth had just been severed when suddenly the patient became pallid, respiration ceased, and it was found that the heart had stopped. As artificial respiration produced no effect I thrust my hand up through the abdomen and found the heart in a similar condition to that in the foregoing case. In this case, however, only two or three squeezes were necessary to set the heart going again and the patient made an uneventful recovery.

Aberdeen.

\section{A PRELIMINARY NOTE ON}

\section{THE PRESENCE OF PIGMENT CONTAIN-} ING IRON IN THE THYROID

\section{GLAND}

BY G. LOVELL GULLAND, M.A., B.Sc., M.D. EdIN., F.R.C.P. EDIN.

ASSISTANT PHTSICIAN TO THE ROFAL INFIRMARY AAND PHYSICIAN TO THE CHALMERS AND ROYAL VICTORIA HOSPITALS, EDINBURGH ;

\section{AND}

ALEXANDER GOODALL, M.D. EDIN., F.R.C.P. EdIN. CLINICAL TUTOR, ROYAL INFIRMARY; SENIOR DEMONSTRATOR OF PHYSIOLOGY, SCHOOL OF MEDICINE, FDINBURGH.

(From the Laboratory of the Royal College of Physicians, Edinburgh.)

IN the course of a histological study of the blood diseases we have on several occasions noticed the presence of pigment giving the free iron reaction in the thyroid. Unfortunately the thyroid had not been preserved in many instances, but we now propose (1) to describe the appearances in six cases; and (2) to give an account of the pigmentary changes in the thyroid gland of animals after blood destruction by hæmolytic agents.

Methods.-The gland tissue was fixed in sublimated formalin and sections were stained with eosin and methylene blue to show the general structure. To demonstrate iron we placed sections in a mixture of potassium ferrocyanide and hydrochloric acid and afterwards counter-stained them with carm-alum. In carrying out the latter method we were careful to avoid the use of metal instruments and to use glass vessels only.

1. CASE 1. Pernicious ancemia with marked pigmentary changes in the organs.-Each of a series of sections of the thyroid gland showed an area of about the size of a pin's head where there was a marked iron reaction. This was found to consist of a group of thyroid cells, most of which were packed with a yellow coloured pigment and were enlarged to about 20 times their normal size. Many of the neighbouring acini showed no pigmentation but here and there throughout the sections were large, irregularly shaped cells full of pigment lying in the fibrous tissue between the acini. All the pigment gave the free iron reaction.

CASE 2. Pernicious ancmia.- The thyroid had undergone

1 Grants towards the expenses of this research were received from the Carnegie Trust and the Mason Fund of the laboratory. 